\section{(C) OPEN ACCESS}

\title{
Potential deaths averted in USA by replacing cigarettes with e-cigarettes
}

\author{
David T Levy, ${ }^{1}$ Ron Borland, ${ }^{2}$ Eric N Lindblom, ${ }^{3}$ Maciej L Goniewicz, ${ }^{4}$ Rafael Meza, ${ }^{5}$ \\ Theodore R Holford, ${ }^{6}$ Zhe Yuan, ${ }^{7}$ Yuying Luo, ${ }^{7}$ Richard J O'Connor, ${ }^{4}$ Raymond Niaura, ${ }^{8}$ \\ David B Abrams ${ }^{1,8}$
}

\begin{abstract}
- Additional material is published online only. To view please visit the journal online (http://dx.doi.org/10.1136/ tobaccocontrol-2017-053759).
\end{abstract}

For numbered affiliations see end of article.

\section{Correspondence to}

Dr David T Levy, Department of Oncology, Lombardi Comprehensive Cancer Center, Georgetown University Medical Center, 3300 Whitehaven St, NW, Suite 4100, Washington, DC 20007, USA;

DL777@georgetown.edu

Received 19 March 2017 Revised 11 July 2017

Accepted 5 August 2017 Published Online First 2 October 2017

\section{SLinked}

- http://dx.doi.org/10.1136/ tobaccocontrol-2017-053969

CrossMark

To cite: Levy DT, Borland R, Lindblom $\mathrm{EN}$, et al.

Tob Control 2018;27:18-25.

\section{ABSTRACT}

Introduction US tobacco control policies to reduce cigarette use have been effective, but their impact has been relatively slow. This study considers a strategy of switching cigarette smokers to e-cigarette use ('vaping') in the USA to accelerate tobacco control progress.

Methods A Status Quo Scenario, developed to project smoking rates and health outcomes in the absence of vaping, is compared with Substitution models, whereby cigarette use is largely replaced by vaping over a 10-year period. We test an Optimistic and a Pessimistic Scenario, differing in terms of the relative harms of e-cigarettes compared with cigarettes and the impact on overall initiation, cessation and switching. Projected mortality outcomes by age and sex under the Status Quo and E-Cigarette Substitution Scenarios are compared from 2016 to 2100 to determine public health impacts. Findings Compared with the Status Quo, replacement of cigarette by e-cigarette use over a 10-year period yields 6.6 million fewer premature deaths with 86.7 million fewer life years lost in the Optimistic Scenario. Under the Pessimistic Scenario, 1.6 million premature deaths are averted with 20.8 million fewer life years lost. The largest gains are among younger cohorts, with a 0.5 gain in average life expectancy projected for the age 15 years cohort in 2016 .

Conclusions The tobacco control community has been divided regarding the role of e-cigarettes in tobacco control. Our projections show that a strategy of replacing cigarette smoking with vaping would yield substantial life year gains, even under pessimistic assumptions regarding cessation, initiation and relative harm.

\section{INTRODUCTION}

Harms from cigarette smoking remain unacceptably high even though smoking prevalence in the USA has decreased markedly over the past 50 years. ${ }^{12}$ Two of three long-term smokers will likely die prematurely of a smoking-attributable disease. ${ }^{3-5}$ Although many tobacco control policies, such as higher cigarette taxes, smoke-free public places, media campaigns, cessation treatment programmes and advertising restrictions, have already been implemented with substantial effectiveness, their pace in averting preventable deaths has been relatively slow and their potential to secure quick and substantial new smoking declines is limited. ${ }^{67}$ Accordingly, tobacco control experts and national governments have begun considering what might be done to accelerate declines in tobacco-caused health harms and eventually eliminate all tobacco consumption (often termed an 'endgame'). The 2014 US Surgeon
General Report recommended an endgame strategy for the tobacco epidemic. ${ }^{6}$ Finland, New Zealand, Hong Kong and Ireland have already set the goal of reaching an endgame. ${ }^{8}$

While some refer to an endgame for all tobacco, most appear to focus on cigarettes as a more realistic and most important target, since they cause the vast majority of harm. ${ }^{79-16}$ However, a credible plan to minimise cigarette use has yet to be implemented. At the same time, emerging nicotine-delivery products, such as e-cigarettes, call for an updating of traditional tobacco control strategies to better address new opportunities and threats that they present. ${ }^{17}$

Rather than focusing on policies designed exclusively to reduce cigarette use, some public health experts suggest a complementary approach to encourage the use of less harmful nicotine delivery products, such as e-cigarettes, as a substitute for cigarettes. ${ }^{6}{ }^{18-21}$ Some public health experts and officials fear that e-cigarette use ('vaping') may increase overall tobacco-related harms by serving as a gateway to smoking or prompting smokers to vape or engage in dual use instead of quitting all use. ${ }^{22-25}$ However, evidence is mounting that e-cigarettes deliver only a small percentage of the toxicants delivered by cigarettes. ${ }^{26-32}$ In addition, newer e-cigarettes models have been shown to more efficiently deliver nicotine $e^{293033}$ than older models and provide sensorimotor experiences and 'throat-hit' similar to smoking, ${ }^{34}$ thus increasing their potential to serve as effective substitutes for cigarettes.

The goal of this paper is to show the potential health impact from an endgame strategy directed at replacing all or most cigarette smoking by e-cigarette use over a 10 -year period. The 10 -year time frame is used for illustrative purposes to show the potential health gains that could be secured by a potent switching-based strategy. To address the major concerns about switching smokers to e-cigarettes, some of the projections assume a much smaller net reduction in health harms from switching to e-cigarette from cigarette use than existing research suggests, and that the switching strategy will increase initiation into regular vaping by youth and others who would not otherwise use any nicotine delivery products and will prompt some smokers who would otherwise have quit all tobacco and nicotine use to instead use e-cigarettes. To distinguish the effect of policies on younger and older cohorts, we present separate analyses for the cohorts age 15 years and age 35 years in 2016 . 


\section{METHODS}

The analysis begins with a Status Quo Scenario for smoking rates and health outcomes. E-cigarette Substitution models are then developed in which cigarette use is replaced by vaping. Projected mortality and life years lost (LYL) under the Status Quo and E-cigarette Substitution models are compared to determine the public health impact.

To reflect the population of smokers alive today in USA, we confine the analysis to the population age 15 years through age 99 years in 2016. Projections are applied through the year 2100 to incorporate the potential health effects of those at younger ages. The model was built in Excel for transparency and to facilitate use by interested parties. The model equations, an explicit statement of the assumptions, and further details, are provided in supplement 1 technical appendix.

\section{Status Quo Scenario}

The Status Quo Scenario focuses on cigarette use and is initialised in 2016 with the population classified as never, current and former cigarette smokers. Due to data limitations and to simplify the analysis, the Status Quo Scenario only considers cigarettes, and does not include smokeless tobacco, e-cigarettes or cigars.

\section{Future cigarette use}

Smoking rates are projected forward using age-specific and sex-specific initiation and cessation rates, and age-specific, sex-specific and smoking status-specific mortality rates. Holford et $a l^{135}$ developed the initiation and cessation rates by applying an age-period-cohort statistical model to data from the 1965-2012 National Health Interview Surveys while correcting for bias due to higher mortality among current and former smokers. They were validated by comparing the smoking prevalence projections based on these initiation and cessation rates over the period 1965 through 2010 against observed rates. ${ }^{34}$ Age-specific, sex-specific and cohort-specific initiation and cessation rates were used to project forward current, former and never smoker rates from their initial 2016 levels. To distinguish between successful cessation and short-term cessation followed by relapse, cessation is measured as having quit smoking for at least 2 years. All-cause cohort life tables subclassified by smoking status (never, former and current) were developed for the 1864-1980 birth cohorts, ${ }^{36}$ and projected forward ${ }^{35}$ using data on smoking prevalence and relative risks by age, sex and smoking status derived from the first two American Cancer Society Cancer Prevention Studies and the smoking prevalence data described above.

\section{Mortality outcomes}

Under the Status Quo, the number of smoking-attributable deaths for current smokers is calculated by age, sex and year as the product of their excess mortality risks (ie, current smoker mortality rate minus never smoker mortality rate) multiplied by the number of smokers. A parallel process is used to derive estimates for former smokers. The numbers of smoking-attributable deaths for current and former smokers are combined and then multiplied by the expected years of life remaining of a never smoker in their age group to estimate LYL from smoking.

\section{E-cigarette Substitution Scenarios}

Starting with the same proportions of smokers, former smokers and never smokers as in the Status Quo Scenario, the two E-cigarette Substitution Scenarios were constructed to show the impact of substituting e-cigarette use for cigarette smoking. The Optimistic Scenario is based primarily on current use patterns in e-cigarettes and published evaluations of harm reduction, while the Pessimistic Scenario is intended to reflect the 'worst case' of suggested harms (eg, with e-cigarettes more harmful than the science indicates), and the switching strategy substantially increasing vaping beyond those who would have smoked in the Status Quo Scenario.

\section{Future cigarette and e-cigarette use}

We assume that the prevalence of cigarette use will be reduced to a $5 \%$ residual prevalence of cigarette use in the Optimistic Scenario and to $10 \%$ in the Pessimistic Scenario. This residual of cigarette smokers would reflect those unwilling or unable to quit cigarettes as well as those who initiate e-cigarette use and progress to smoking. The substitution of e-cigarette for cigarette use under the Optimistic Scenario is modelled as a $10 \%$ reduction in the difference between the 2016 smoking prevalence and the $5 \%$ residual at each age to each cohort each year over 10 years starting in 2017, that is, replacing $10 \%$ of cigarette by e-cigarette users over 10 years, so that a residual of 5\% cigarette smoking prevalence remains in 2026. In the Pessimistic Scenario, the corresponding annual reduction is calculated to instead yield a $10 \%$ prevalence of cigarette use after 10 years.

Those who replace cigarettes with e-cigarette use before age 40 years are treated as never smokers using e-cigarettes, since their risks as former smokers will be close to that of never smokers. ${ }^{38}$ Those who replace cigarette with e-cigarette use after age 40 years are treated as former smokers using e-cigarettes.

In the Status Quo Scenario, most never smokers initiate cigarette smoking by age 24 years. Under the Optimistic Scenario, never smokers who would have smoked cigarettes instead become e-cigarette users at the same rates as initiation of cigarette use in the Status Quo Scenario after the 5\% smoking prevalence is reached, reflecting the small percentage of never smokers who have been found to use e-cigarettes. ${ }^{39-41}$ Under the Pessimistic Scenario, e-cigarette initiation is assumed to occur at $150 \%$ of the Status Quo smoking initiation rate to reflect some renormalisation of nicotine use. ${ }^{22-25}$

The Optimistic and Pessimistic Scenarios are also distinguished by the rate of cessation from e-cigarettes. Like cigarette smokers, e-cigarette users may quit e-cigarette use for health or other reasons. Indeed, some studies have found e-cigarettes vary substantially in nicotine delivery and can have lower nicotine addiction liability than when the nicotine is delivered via inhaled smoke from the combustion of tobacco smoking. ${ }^{33} 42-45$ Under the Optimistic Scenario, e-cigarette users each year quit at the same age-specific and sex-specific cessation rate as smokers in the Status Quo Scenario. Under the Pessimistic Scenario, e-cigarette users each year quit at half the rate of cigarette smokers in the Status Quo Scenario.

The final distinction between the Optimistic and Pessimistic Scenarios is the expected risk of e-cigarette use, which is measured here relative to the excess risk of cigarettes. Although the health risks have yet to be thoroughly characterised, e-cigarettes appear to have much lower levels of toxicants than cigarettes ${ }^{26-29} 32$ Under the Optimistic Scenario, an excess risk of e-cigarette use at $5 \%$ of cigarette excess risk is applied to current e-cigarette users, reflecting estimates from published reports. ${ }^{27} 46$ We assume that the risk to former smokers from using e-cigarettes is proportional to the difference in risks between current and former smokers. Applying the $5 \%$ excess risk of exclusive e-cigarette use to former smokers using e-cigarettes, their excess risk is estimated as 
that of former smokers plus $(5 \% \mathrm{x}$ (current smoker mortality rate - former smoker mortality rate)). Although worst case estimates of excess risks have not been published, we apply an excess risk of $40 \%$ for e-cigarette use under the Pessimistic Scenario, as suggested by some critics of vaping. ${ }^{47} 48$ Parallel to the Optimistic Scenario, the $40 \%$ risk is then also scaled by the difference in risks between current and former smokers.

\section{Health outcomes}

For the Optimistic and Pessimistic E-Cigarette Substitution Scenarios, total premature deaths and LYL are calculated for e-cigarette users that never smoked, e-cigarette users among former smokers, former e-cigarette users, and current and former smokers who have not yet switched to e-cigarette use. At each age, excess risks are multiplied by the number of individuals in each of these categories and summed to obtain premature deaths and multiplied by expected life years remaining of a never smoker to obtain LYL.

\section{Public health impact of replacing cigarette use by e-cigarettes}

For the Optimistic and Pessimistic Scenarios, the public health impact is estimated by subtracting total premature deaths in each of these Scenarios from those in the Status Quo Scenario, and similarly for LYL. The public health impact is first determined for each cohort by summing overall remaining ages, and then summed over cohorts to determine the overall impact. By dividing the change in LYL by the 2016 population, we obtain a measure of the impact of the E-cigarette Substitution Scenario on life expectancy.

\section{RESULTS}

Table 1 contains the premature deaths and LYL by age predicted under the Status Quo and the two E-cigarette Substitution Scenarios. Supplement 2 contains additional results by sex and for different levels of e-cigarette risk.

\section{Status Quo Scenario}

Under the Status Quo Scenario, smoking prevalence (age $15-99$ years) in 2016 is $19.3 \%$ for men and $14.1 \%$ for women, and declines over time for cohorts above age 24 years in 2016 . A cumulative total of 26.1 million (18.8 million male; 7.3 million female) premature deaths and 248.6 million (177.9 million male; 70.8 million female) LYL are projected.

\section{E-Cigarette Substitution Scenarios}

Under the Optimistic Scenario, a cumulative total of 19.5 million (14.0 million male; 5.5 million female) premature deaths and 161.9 million (115.0 million male; 46.9 million female) LYL are projected. Compared with the Status Quo Scenario, a net gain of 6.6 million ( 4.8 million male; 1.7 million female) fewer premature deaths and 86.7 million (62.9 million male; 23.9 million female) fewer LYL are projected, representing 25\% fewer premature deaths and 35\% fewer LYL. The reduction in LYL translates to an increased average life expectancy of 0.33 ( 0.49 male; 0.18 female) years for the 2012 age 15 years and above population.

Under the Pessimistic Scenario, the e-cigarette prevalence is slightly larger in the early years (due to the $10 \%$ rather than $5 \%$ residual smoking prevalence), but does not decline as rapidly over time as in the Optimistic Scenario. With a 10\% residual prevalence, the models allows no switching to e-cigarette use after age 61 years for men and after age 54 years for women, since smoking rates are $10 \%$ at those ages in 2016 . Health outcomes are worse than the Optimistic Scenario with a cumulative total of 24.4 million ( 17.4 million male; 7.0 million female) premature deaths and 227.8 million (160.0 million male; 67.8 million female) LYL. Compared with the Status Quo Scenario, a net gain of 1.6 million ( 1.4 million male; 0.3 million female) representing $6 \%$ fewer premature deaths and 20.8 million (17.8 million male; 3.0 million female) representing $8 \%$ fewer LYL are projected. Average life expectancy increases 0.08 years $(0.14$ male; 0.02 female).

\section{The 2001 birth cohort}

As shown in table 2, male smoking prevalence under the Status Quo Scenario for the 2001 birth cohort (age 15 years in 2016) is $4.5 \%$ at age 15 years, increasing to $21.7 \%$ at age 25 years, and decreasing to $10.6 \%$ at age 55 years. Female smoking prevalence is substantially lower beginning at $2.4 \%$, increasing to $15.2 \%$ at age 25 years and falling to $8.3 \%$ at age 55 years. A cumulative total

Table 1 Status quo and e-cigarette substitution, premature deaths and life years lost for all cohorts, men and women combined

\begin{tabular}{|c|c|c|c|c|c|c|c|c|}
\hline Outcome & Year 2016 & 2026 & 2060 & 2080 & 2100 & $\begin{array}{l}\text { Cumulative } \\
(2016-2100)\end{array}$ & $\begin{array}{l}\text { Deaths prevented/ } \\
\text { life years gained* }\end{array}$ & $\begin{array}{l}\% \text { Change relative } \\
\text { to status quo }\end{array}$ \\
\hline \multicolumn{9}{|l|}{ Status Quo Scenario† } \\
\hline Premature deaths & 461588 & 470743 & 316556 & 167037 & 2905 & 26065448 & & \\
\hline Life years lost & 5689458 & 5625286 & 2626503 & 685593 & 1852 & 248639532 & & \\
\hline \multicolumn{9}{|l|}{ Optimistic Scenarioł } \\
\hline Premature deaths & 461588 & 380832 & 233243 & 56399 & 459 & 19484289 & 6581159 & $25.2 \%$ \\
\hline Premature deaths & 461588 & 456297 & 298689 & 127706 & 2188 & 24432065 & 1633383 & $6.3 \%$ \\
\hline Life years lost & 5689458 & 5261398 & 2319388 & 528926 & 1396 & 227835203 & 20804329 & $8.4 \%$ \\
\hline
\end{tabular}

*Life years gained=life years lost in Status Quo Scenario - Life years lost in E-cigarette Substitution Scenario.

tStatus Quo Scenario: smoking rates evolve from initial 2016 levels based on age, gender and cohort-specific smoking initiation and cessation rates in the absence of e-cigarette use.

¥0ptimistic Scenario: e-cigarettes excess risk 5\% of smoking, $5 \%$ of the population continues to initiate cigarette smoking or remain as smokers, the remainder of never smokers then initiate e-cigarette use at the rate of cigarette smoking initiation in the Status Quo Scenario, and both smokers and e-cigarette users quit at the rate of smokers in the Status Quo Scenario.

§Pessimistic Scenario: e-cigarettes excess risk $40 \%$ of smoking, $10 \%$ of the population continues to initiate cigarette smoking or remain as smokers, the remainder of never smokers then initiate e-cigarette use at the $150 \%$ rate of cigarette smoking initiation in the Status Quo Scenario, and e-cigarette users quit at $50 \%$ of the rate of smokers in the Status Quo Scenario and smokers quit at the Status Quo cessation rate. 
Table 2 Status quo and e-cigarette substitution, premature deaths and life years lost, men and women born in 2001 (age 15 years in 2016)

\begin{tabular}{|c|c|c|c|c|c|c|c|}
\hline \multirow[b]{2}{*}{ Outcomes } & Year & 2016 & 2026 & 2056 & \multirow{2}{*}{$\begin{array}{l}\text { Cumulative } \\
(2016-2100)\end{array}$} & \multirow{2}{*}{$\begin{array}{l}\text { Deaths prevented/ } \\
\text { life years gained* }\end{array}$} & \multirow{2}{*}{$\begin{array}{l}\% \text { Change relative } \\
\text { to status quo }\end{array}$} \\
\hline & Age, years & 15 & 25 & 55 & & & \\
\hline \multicolumn{8}{|l|}{ Male } \\
\hline \multicolumn{8}{|c|}{ Status Quo Scenario† } \\
\hline \multirow[t]{3}{*}{ Prevalence } & Never smoker & $95.5 \%$ & $75.5 \%$ & $72.8 \%$ & & & \\
\hline & Cigarette smoker & $4.5 \%$ & $21.7 \%$ & $10.6 \%$ & & & \\
\hline & Former smoker & $0.0 \%$ & $2.8 \%$ & $16.7 \%$ & & & \\
\hline Premature deaths & & 0 & 0 & 1381 & 176915 & & \\
\hline Life years lost & & 0 & 0 & 43507 & 2101908 & & \\
\hline \multicolumn{8}{|c|}{ Optimistic Scenarioł } \\
\hline \multirow[t]{7}{*}{ Prevalence } & Never smoker & $95.5 \%$ & $75.5 \%$ & $72.5 \%$ & & & \\
\hline & Cigarette smoker & $4.5 \%$ & $5.0 \%$ & $2.1 \%$ & & & \\
\hline & $\begin{array}{l}\text { Former smoker }>\text { age } \\
40 \text { years }\end{array}$ & $0.0 \%$ & $0.0 \%$ & $1.2 \%$ & & & \\
\hline & $\begin{array}{l}\text { E-cigarettes } \\
\text { exclusive }\end{array}$ & $0.0 \%$ & $16.7 \%$ & $8.7 \%$ & & & \\
\hline & $\begin{array}{l}\text { Former smoker<age } \\
40 \text { years }\end{array}$ & $0.0 \%$ & $2.8 \%$ & $10.5 \%$ & & & \\
\hline & $\begin{array}{l}\text { E-cigarette/former } \\
\text { smoker }\end{array}$ & $0.0 \%$ & $0.0 \%$ & $0.0 \%$ & & & \\
\hline & $\begin{array}{l}\text { Former E-cigarette } \\
\text { user }\end{array}$ & $0.0 \%$ & $0.0 \%$ & $4.9 \%$ & & & \\
\hline Premature deaths & & 0 & 0 & 301 & 29556 & 147359 & $83.3 \%$ \\
\hline Life years lost & & 0 & 0 & 9496 & 402823 & 1699085 & $80.8 \%$ \\
\hline \multicolumn{8}{|c|}{ Pessimistic Scenario§ } \\
\hline Premature deaths & & 0 & 0 & 1247 & 141287 & 35629 & $20.1 \%$ \\
\hline Life years lost & & 0 & 0 & 39308 & 1793892 & 308016 & $14.7 \%$ \\
\hline \multicolumn{8}{|l|}{ Female } \\
\hline \multicolumn{8}{|c|}{ Status Quo Scenario† } \\
\hline \multirow[t]{3}{*}{ Prevalence } & Never smoker & $97.6 \%$ & $82.8 \%$ & $79.4 \%$ & & & \\
\hline & Cigarette smoker & $2.4 \%$ & $15.2 \%$ & $8.3 \%$ & & & \\
\hline & Former smoker & $0.0 \%$ & $2.1 \%$ & $12.3 \%$ & & & \\
\hline Premature deaths & & 0 & 0 & 369 & 63244 & & \\
\hline Life years lost & & 0 & 0 & 12513 & 711172 & & \\
\hline \multicolumn{8}{|l|}{ Optimistic Scenarioł } \\
\hline \multirow[t]{7}{*}{ Prevalence } & Never smoker & $97.6 \%$ & $82.8 \%$ & $79.4 \%$ & & & \\
\hline & Cigarette smoker & $2.4 \%$ & $5.0 \%$ & $2.1 \%$ & & & \\
\hline & $\begin{array}{l}\text { Former smoker }>\text { age } \\
40 \text { years }\end{array}$ & $0.0 \%$ & $0.0 \%$ & $1.3 \%$ & & & \\
\hline & $\begin{array}{l}\text { E-cigarettes } \\
\text { exclusive }\end{array}$ & $0.0 \%$ & $10.2 \%$ & $6.2 \%$ & & & \\
\hline & $\begin{array}{l}\text { Former smoker <age } \\
40 \text { years }\end{array}$ & $0.0 \%$ & $2.1 \%$ & $7.5 \%$ & & & \\
\hline & $\begin{array}{l}\text { E-cigarette/former } \\
\text { smoker }\end{array}$ & $0.0 \%$ & $0.0 \%$ & $0.0 \%$ & & & \\
\hline & $\begin{array}{l}\text { Former e-cigarette } \\
\text { user }\end{array}$ & $0.0 \%$ & $0.0 \%$ & $3.5 \%$ & & & \\
\hline Premature deaths & & 0 & 0 & 109 & 14297 & 48947 & $77.4 \%$ \\
\hline Life years lost & & 0 & 0 & 3687 & 181846 & 529326 & $74.7 \%$ \\
\hline \multicolumn{8}{|c|}{ Pessimistic Scenario§ } \\
\hline Premature deaths & & 0 & 0 & 387 & 61469 & 1775 & $2.8 \%$ \\
\hline Life years lost & & 0 & 0 & 13106 & 737757 & -26585 & $-3.7 \%$ \\
\hline
\end{tabular}

* Life years gained=life years lost in Status Quo - Life years lost in E-cigarette Substitution Scenario.

†Status Quo Scenario: Smoking Rates evolve from initial 2016 levels based on age, gender and cohort-specific smoking initiation and cessation rates in the absence of e-cigarette use.

¥0ptimistic Scenario: e-cigarettes excess risk 5\% of smoking, $5 \%$ of the population continues to initiate cigarette smoking or remain as smokers, the remainder of never smokers then initiate e-cigarette use at the rate of cigarette smoking initiation in the Status Quo Scenario, and both smokers and e-cigarette users quit at the rate of smokers in the Status Quo Scenario.

§Pessimistic Scenario: e-cigarettes excess risk $40 \%$ of smoking, $10 \%$ of the population continues to initiate cigarette smoking or remain as smokers, the remainder of never smokers then initiate e-cigarette use at the 150\% rate of cigarette smoking initiation in the Status Quo Scenario, and e-cigarette users quit at $50 \%$ of the rate of smokers in the Status Quo Scenario and smokers quit at the Status Quo cessation rate. 
of 240 thousand (176.9 thousand male; 63.2 thousand female) premature deaths and 2.8 million $(2.1$ million male; 0.7 million female) LYL are attributed to smoking for the 2001 birth cohort. For the same cohort under the Optimistic Scenario, 29.6 thousand premature deaths and 402.8 thousand LYL are projected for men and 14.3 thousand premature deaths and 181.8 thousand LYL for women, yielding a net public health gain of 196.3 thousand fewer premature deaths and 2.2 million fewer LYL, representing $82 \%$ fewer premature deaths and $79 \%$ fewer LYL. Life expectancy increases by 0.5 years ( 0.8 male; 0.3 female), largely reflecting the 2.9 years (3.7 male; 1.7 female) increase in life expectancy of otherwise smokers. Compared with the Status Quo Scenario, 16\% fewer premature deaths and 10\% fewer LYL are projected under the Pessimistic Scenario.

\section{The 1981 birth cohort}

As shown in table 3, male (female) smoking prevalence under the Status Quo Scenario for the 1981 birth cohort (age 35 years in 2016 ) begins at $28.4 \%(21.0 \%)$, decreasing to $21.4 \%(16.3 \%)$ at age 45 years and $5.5 \%(3.7 \%)$ at age 75 years. Compared with the Status Quo Scenario, the projected net public health gain with the Optimistic Scenario is 160.5 thousand (119.9 thousand male; 40.5 thousand female) or $43 \%$ fewer premature deaths and 2.2 million ( 1.7 million male; 559.8 thousand female) or $52 \%$ fewer LYL. For the Pessimistic Scenario, 13\% fewer premature deaths and $17 \%$ fewer LYL are projected.

\section{DISCUSSION}

Our analysis shows that a hypothetical substitution of e-cigarette for cigarette use provides tremendous potential to avert premature deaths due to smoking, with only a relatively small amount of premature deaths due to e-cigarettes. Among those aged 15 years and above in 2016, almost 6.6 million fewer premature deaths and 86.7 million fewer LYL due to cigarette use occur in the Optimistic Scenario. The average 15-year-old would increase their life expectancy by 0.5 years, reflecting the increased life span of those who have, or would otherwise have smoked cigarettes, switching to e-cigarettes. Our results also show that although there would still be considerable premature deaths and LYL in all scenarios (table 1), these are primarily due to the impact of smoking among those aged 35 years and older in 2016 (tables 2 and 3). This estimate corresponds, in our view, to reasonable estimates of initiation, cessation and e-cigarette risk known to date. ${ }^{19} 49$

Even in the Pessimistic Scenario, where we allow for longterm ongoing renormalisation of tobacco use in terms of e-cigarette initiation, reduced cessation, far smaller reductions in harm from e-cigarettes than existing science indicates, and a residual prevalence of $10 \%$, there are still overall net gains in averted premature deaths and LYL. Accordingly, this study suggests that, even under a worst case scenario, an endgame strategy that successfully prompted most cigarette smokers to switch to vaping would secure substantial public health gains.

In addition to the reductions in mortality, further health benefits would accrue from reduced disability, tobacco-related disease incidence and exposure to secondhand smoke. The reduced disability and disease burden would also translate directly into lower medical costs associated with cancer, chronic obstructive pulmonary disease and heart disease, reduced productivity losses due to death and disease primarily among those of ages 40 years through 64 years, and improved quality of life. ${ }^{6}$ These gains can be expected to reduce health disparities, since smoking rates are highest among those with lower income and education. ${ }^{6}$
In addition, secondhand exposure to e-cigarette aerosol has been found to be less extensive and less harmful than exposure to cigarette smoke ${ }^{50}{ }^{51}$ thus reducing mortality and morbidity in non-smokers.

Unlike previous models of e-cigarette use, ${ }^{49}{ }^{52-54}$ our model was not developed to predict future e-cigarette and cigarette use based on past trends. Rather the aim was to examine a hypothetical endgame strategy of reducing cigarette use through switching to e-cigarettes. As with any hypothetical modelling exercise, a number of limitations are worth noting.

The Status Quo Scenario is developed based on past smoking uptake and cessation rates through the years 2012, prior to the major growth in e-cigarette use. 5556 The projections do not incorporate tobacco control policy changes and the effect of increases in e-cigarette use that have occurred after 2012. To the extent that e-cigarette use and tobacco control policies implemented since 2012 would have already reduced cigarette use, our estimates of the gains under the Optimistic and Pessimistic Scenarios would be reduced.

Our models were limited to cigarette and e-cigarette use, and do not incorporate the use of other nicotine delivery products, including smokeless tobacco, water pipes and cigars. While use of these other products are relatively minor contributors to overall tobacco-related harms, policies should be directed at all combustible tobacco to reduce the likelihood of substituting other harmful smoked products, such as little cigars. ${ }^{57}$ Taking into account the substitution of e-cigarettes for these other products would further increase the estimated public health gains from an e-cigarette substitution strategy.

The choice of a $10 \%$ residual rate of smokers in the Pessimistic Scenario and a 5\% residual in the Optimistic Scenario were included to allow for the possibility that some current cigarette smokers would be unlikely to quit. The residual prevalence of cigarette smokers will depend on the potency of policies directed at cigarette use. Traditional cigarette-oriented policies, including significant cigarette tax increases, ${ }^{1058-60}$ large and graphic pictorial warnings on cigarette packages, ${ }^{61}$ and retail point-of-sale restrictions on advertising displays, ${ }^{62}$ have each been projected to reduce smoking prevalence by at least $10 \%$ in relative terms. A previous study estimated that strong policies (including a $\$ 2.00$ tax increase) would reduce cigarette use by $40 \%$. A nicotine reduction policy may substantially reduce cigarette use if properly enforced, ${ }^{16} 6364$ especially when accompanied by a more permissive approach to e-cigarettes. ${ }^{65}$ In addition, a menthol cigarette ban may encourage cessation and discourage youth and young adults from cigarette use. ${ }^{66}$ Synergies may enhance the effect of these policies.

Substitution from cigarettes to e-cigarettes will also depend on the policies directed at e-cigarette use. Information dissemination policies that provide the best available information on the relative risks of e-cigarettes are likely to encourage switching to e-cigarette use. In addition, just as innovations have improved both the appeal and delivery of nicotine in a satisfying manner, ${ }^{29} 3033$ innovations are likely to improve the substitutability of e-cigarettes for cigarettes, unless there are major regulatory hurdles for introducing new products. Once smokers were switched to vaping and any significant new re-emergence of smoking were discouraged, the same tools that have successfully been employed in reducing cigarette use, such as increasing e-cigarette taxes, ${ }^{67}$ raising and enforcing the minimum purchase age, ${ }^{37}$ and restricting marketing directed at youth, could be applied to e-cigarette use if vaping were found to be more harmful than current evidence suggests or if e-cigarette use was at unacceptably high levels through normalisation of vaping. 
Table 3 Status quo and e-cigarette substitution, premature deaths and life years lost, men and women, cohort born in 1981 (age 35 years in 2016 )

\begin{tabular}{|c|c|c|c|c|c|c|c|}
\hline \multirow[b]{2}{*}{ Outcomes } & Year & 2016 & 2026 & 2056 & \multirow{2}{*}{$\begin{array}{l}\text { Cumulative } \\
(2016-2080)\end{array}$} & \multirow{2}{*}{$\begin{array}{l}\text { Deaths prevented/ } \\
\text { life years gained* }\end{array}$} & \multirow{2}{*}{$\begin{array}{l}\% \text { Change relative } \\
\text { to status quo }\end{array}$} \\
\hline & Age, years & 35 & 45 & 75 & & & \\
\hline \multicolumn{8}{|l|}{ Male } \\
\hline \multicolumn{8}{|c|}{ Status Quo Scenario† } \\
\hline \multirow[t]{3}{*}{ Prevalence } & Never smoker & $56.1 \%$ & $55.9 \%$ & $58.4 \%$ & & & \\
\hline & Cigarette smoker & $28.4 \%$ & $21.4 \%$ & $5.5 \%$ & & & \\
\hline & Former smoker & $15.5 \%$ & $22.7 \%$ & $36.1 \%$ & & & \\
\hline Premature deaths & & 0 & 1110 & 5927 & 278703 & & \\
\hline Life years lost & & 0 & 42538 & 70549 & 3217819 & & \\
\hline \multicolumn{8}{|l|}{ Optimistic Scenarioł } \\
\hline \multirow[t]{7}{*}{ Prevalence } & Never smoker & $56.1 \%$ & $55.8 \%$ & $56.8 \%$ & & & \\
\hline & Cigarette smoker & $28.4 \%$ & $5.0 \%$ & $1.2 \%$ & & & \\
\hline & $\begin{array}{l}\text { Former smoker }>\text { age } \\
40 \text { years }\end{array}$ & $15.5 \%$ & $17.6 \%$ & $25.4 \%$ & & & \\
\hline & $\begin{array}{l}\text { E-cigarettes } \\
\text { exclusive }\end{array}$ & $0.0 \%$ & $8.4 \%$ & $3.0 \%$ & & & \\
\hline & $\begin{array}{l}\text { Former smoker<age } \\
40 \text { years }\end{array}$ & $0.0 \%$ & $3.8 \%$ & $3.9 \%$ & & & \\
\hline & $\begin{array}{l}\text { E-cigarette/former } \\
\text { smoker }\end{array}$ & $0.0 \%$ & $8.1 \%$ & $2.5 \%$ & & & \\
\hline & $\begin{array}{l}\text { Former e-cigarette } \\
\text { user }\end{array}$ & $0.0 \%$ & $1.3 \%$ & $7.3 \%$ & & & \\
\hline Premature deaths & & 0 & 300 & 3412 & 158760 & 119943 & $43.0 \%$ \\
\hline Life years lost & & 0 & 11497 & 40613 & 1559546 & 1658273 & $51.5 \%$ \\
\hline \multicolumn{8}{|c|}{ Pessimistic Scenario§ } \\
\hline Premature deaths & & 0 & 777 & 5123 & 236850 & 41853 & $15.0 \%$ \\
\hline Life years lost & & 0 & 29783 & 60982 & 2621426 & 956393 & $18.5 \%$ \\
\hline \multicolumn{8}{|l|}{ Female } \\
\hline \multicolumn{8}{|c|}{ Status Quo Scenariot } \\
\hline \multirow[t]{3}{*}{ Prevalence } & Never smoker & $67.1 \%$ & $66.8 \%$ & $67.6 \%$ & & & \\
\hline & Cigarette smoker & $21.0 \%$ & $16.3 \%$ & $3.7 \%$ & & & \\
\hline & Former smoker & $11.9 \%$ & $16.9 \%$ & $28.7 \%$ & & & \\
\hline Premature deaths & & 0 & 137 & 1924 & 98714 & & \\
\hline Life years lost & & 0 & 5673 & 26525 & 1078282 & & \\
\hline \multicolumn{8}{|l|}{ Optimistic Scenarioł } \\
\hline \multirow[t]{7}{*}{ Prevalence } & Never smoker & $67.1 \%$ & $66.8 \%$ & $67.0 \%$ & & & \\
\hline & Cigarette smoker & $21.0 \%$ & $5.0 \%$ & $1.1 \%$ & & & \\
\hline & $\begin{array}{l}\text { Former smoker }>\text { age } \\
40 \text { years }\end{array}$ & $11.9 \%$ & $13.4 \%$ & $20.9 \%$ & & & \\
\hline & $\begin{array}{l}\text { E-cigarettes } \\
\text { exclusive }\end{array}$ & $0.0 \%$ & $5.8 \%$ & $1.6 \%$ & & & \\
\hline & $\begin{array}{l}\text { Former smoker <age } \\
40 \text { years }\end{array}$ & $0.0 \%$ & $2.6 \%$ & $2.6 \%$ & & & \\
\hline & $\begin{array}{l}\text { E-cigarette/former } \\
\text { smoker }\end{array}$ & $0.0 \%$ & $5.5 \%$ & $1.4 \%$ & & & \\
\hline & $\begin{array}{l}\text { Former e-cigarette } \\
\text { user }\end{array}$ & $0.0 \%$ & $0.9 \%$ & $5.3 \%$ & & & \\
\hline Premature deaths & & 0 & 47 & 1020 & 58186 & 40528 & $41.1 \%$ \\
\hline Life years lost & & 0 & 1936 & 14066 & 518499 & 559782 & $51.9 \%$ \\
\hline \multicolumn{8}{|c|}{ Pessimistic Scenario§ } \\
\hline Premature deaths & & 0 & 108 & 1777 & 89933 & 8781 & $8.9 \%$ \\
\hline Life years lost & & 0 & 4451 & 24492 & 950737 & 127544 & $11.8 \%$ \\
\hline
\end{tabular}

*Life years gained=life years lost in Status Quo Scenario - life years lost in E-cigarette Substitution Scenario.

†Smoking rates evolve from initial 2016 levels based on age, gender and cohort-specific smoking initiation and cessation rates in the absence of e-cigarette use.

$\ddagger$ Optimistic Scenario: e-cigarettes excess risk $5 \%$ of smoking, $5 \%$ of the population continues to initiate cigarette smoking or remain as smokers, the remainder of never smokers then initiate e-cigarette use at the rate of cigarette smoking initiation in the Status Quo Scenario, and both smokers and e-cigarette users quit at the rate of smokers in the Status Quo Scenario.

§Pessimistic Scenario: e-cigarettes excess risk $40 \%$ of smoking, $10 \%$ of the population continues to initiate cigarette smoking or remain as smokers, the remainder of never smokers then initiate e-cigarette use at the $150 \%$ rate of cigarette smoking initiation in the Status Quo Scenario, and e-cigarette users quit at $50 \%$ of the rate of smokers in the Status Quo Scenario and smokers quit at the Status Quo cessation rate. 
Another limitation is that we treated e-cigarettes as a homogeneous category in terms of risks. In fact, products vary in terms of their toxicant content, ${ }^{28}$ price ${ }^{68}$ and desirability. ${ }^{69} \mathrm{We}$ do not yet have evidence of the actual long-term health effects of e-cigarette use. However, applying sensitivity analysis to the Pessimistic Scenario, we found that substitution from cigarettes to e-cigarettes yielded public health gains with excess risks of e-cigarettes relative to cigarettes as high as $71 \%$ for men and $55 \%$ for women. Regardless, prudent product standards to limit known toxicants as much as practical would reduce the range of harm for different types and brands of e-cigarettes, and is likely to increase perceptions by smokers of reduced harm of e-cigarettes relative to cigarettes. If the relative risk of e-cigarettes were to be reduced to $3 \%$ and the residual prevalence to $2.5 \%$, the relative reduction in LYL would increase from $35 \%$ to $44 \%$. Furthermore, heat-not-burn tobacco products have been introduced in some countries, and these may be a better substitute for cigarettes than e-cigarettes, but have higher toxicant levels. While they may impose greater health risks, they are still likely well within the estimates used in our Pessimistic Scenario.

In conclusion, tobacco industry document ${ }^{70}$ reveal an industry strategy of 'divide and conquer' focused primarily on fostering divisions within the tobacco control community regarding modified risk products. Indeed, the tobacco control community has had divided approaches to e-cigarettes, and in the process may have lost focus on cigarettes, the most deadly form of nicotine delivery. Our analysis shows that a strategy of replacing cigarette by e-cigarette use can yield substantial gains, even with conservative assumptions about related risks. Most important, an e-cigarette substitution strategy provides the justification to redouble efforts to target cigarette use, as called for by the WHO Framework Convention for Tobacco Control. ${ }^{71}$ An endgame scenario for cigarettes might well be within reach, if new technologies for delivering nicotine with substantially less harm, but sufficient satisfaction, are harnessed with sufficient passion and political will to aggressively phase out tobacco cigarettes.

What this paper adds

- The 2014 US Surgeon General's Report suggested the need for a new strategy to more quickly end tobacco use, but a credible strategy has not been provided. This paper considers a strategy of switching cigarettes smokers to e-cigarette use in USA to accelerate tobacco control progress.

- Using a previously validated simulation model, our projections show that a strategy of replacing cigarette smoking with e-cigarette use would yield substantial life year gains, even under pessimistic assumptions regarding cessation, initiation and relative harm.

\section{Author affiliations}

'Department of Oncology, Lombardi Comprehensive Cancer Center, Georgetown University Medical Center, Washington, District of Columbia, USA

${ }^{2}$ Nigel Gray Distinguished Fellow in Cancer Prevention, VicHealth Centre for Tobacco Control, The Cancer Council Victoria, Melbourne, Victoria, Australia

${ }^{3} \mathrm{O}^{\prime}$ Neill Institute for National \& Global Health Law, Georgetown University Law Center, Washington, District of Columbia, USA

${ }^{4}$ Department of Health Behavior, Division of Cancer Prevention and Population Studies, Roswell Park Cancer Institute, Buffalo, New York, USA

${ }^{5}$ Department of Epidemiology, School of Public Health, University of Michigan, Ann Arbor, Michigan, USA

${ }^{6}$ Department of Biostatistics, Yale University, New Haven, Connecticut, USA ${ }^{7}$ Lombardi Comprehensive Cancer Center, Georgetown University, Washington, District of Columbia, USA

${ }^{8}$ Schroeder Institute for Tobacco Research and Policy Studies, Truth Initiative, Washington, District of Columbia, USA
Acknowledgements The authors thank Michael Cummings, Medical University of South Carolina, for comments on an earlier draft.

Contributors DTL wrote most of the original paper. DBA and DTL conceived the original idea. $Z Y$ and $Y L$ conducted the analysis and helped write up the methods and results section. RB, RM, TRH, RJO'C, MLG and RN helped with the writing and revisions and contributed to the discussion of methodology.

Funding Funding was received by DTL, DBA, RM and RN from the National Institute on Drug Abuse, under grant R01DA036497. TRH and RM received funding from the Cancer Intervention and Surveillance Modeling Network (CISNET) of the Division of Cancer Control and Population Sciences, NCl under grant U01-CA97450. $\mathrm{RB}, \mathrm{MLG}, \mathrm{RJO} \mathrm{O}^{\mathrm{C}}$ and $\mathrm{DTL}$ received funding from the National Cancer Institute under grant P01-CA200512.

Competing interests MLG received a research grant from Pfizer and served as an advisory board member to Johnson \& Johnson, manufacturers of smoking cessation medications. No other conflicts of interest are declared.

Provenance and peer review Not commissioned; externally peer reviewed.

Data sharing statement The model used in this article and a manual will be made available by Dr. Levy upon request.

Open Access This is an Open Access article distributed in accordance with the Creative Commons Attribution Non Commercial (CC BY-NC 4.0) license, which permits others to distribute, remix, adapt, build upon this work non-commercially, and license their derivative works on different terms, provided the original work is properly cited and the use is non-commercial. See: http://creativecommons.org/ licenses/by-nc/4.0/

(c) Article author(s) (or their employer(s) unless otherwise stated in the text of the article) 2018. All rights reserved. No commercial use is permitted unless otherwise expressly granted.

\section{REFERENCES}

1 Holford TR, Meza R, Warner KE, et al. Tobacco control and the reduction in smokingrelated premature deaths in the United States, 1964-2012. JAMA 2014;311:164-71.

2 Levy DT, Meza R, Zhang Y, et al. Gauging the Effect of U.S. Tobacco Control Policies From 1965 Through 2014 Using SimSmoke. Am J Prev Med 2016;50:535-42.

3 Jha P, Ramasundarahettige C, Landsman V, et al. 21st-century hazards of smoking and benefits of cessation in the United States. N Engl J Med 2013;368:341-50.

4 Thun MJ, Lopez AD, Hartge P. Smoking-related mortality in the United States. N Eng/ I Med 2013;18:368.

5 Carter BD, Abnet CC, Feskanich D, et al. Smoking and mortality--beyond established causes. N Engl I Med 2015;372:631-40.

6 U.S. Department of Health and Human Services. The health consequences of smoking - 50 years of progress: a report of the surgeon general. Atlanta, GA. 2014

7 Warner KE. Tobacco control policies and their impacts. Past, present, and future. Ann Am Thorac Soc 2014;11:227-30.

8 Lykke M, Pisinger C, Glümer C. Ready for a goodbye to tobacco? - Assessment of support for endgame strategies on smoking among adults in a Danish regional health survey. Prev Med 2016;83:5-10.

9 Branston JR, Sweanor D. Big tobacco, E-cigarettes, and a road to the smoking endgame. Int J Drug Policy 2016;29:14-18.

10 Cobiac LJ, Ikeda T, Nghiem N, et al. Modelling the implications of regular increases in tobacco taxation in the tobacco endgame. Tob Control 2015;24:e154-60.

11 Hurt RD, Murphy JG, Dunn WF. Did we finally slay the evil dragon of cigarette smoking in the late 20th century?: unfortunately, the answer is no - the dragon is still alive and well in the 21st century and living in the third world. Shame on us!. Chest 2014;146:1438-43.

12 Kozlowski LT. Prospects for a nicotine-reduction strategy in the cigarette endgame: Alternative tobacco harm reduction scenarios. Int I Drug Policy 2015;26:543-7.

13 Malone R, McDaniel P, Smith E. It is time to plan the tobacco endgame. BMJ 2014;348:91453.

14 Pearson AL, van der Deen FS, Wilson N, et al. Theoretical impacts of a range of major tobacco retail outlet reduction interventions: modelling results in a country with a smoke-free nation goal. Tob Control 2015;24:e32-8.

15 Thomas BP, Gostin LO. Tobacco endgame strategies: challenges in ethics and law. Tob Control 2013;22(Suppl 1):i55-7.

16 Benowitz NL, Donny EC, Hatsukami DK. Reduced nicotine content cigarettes, e-cigarettes and the cigarette end game. Addiction 2017;112:6-7.

17 Kozlowski LT, Abrams DB. Obsolete tobacco control themes can be hazardous to public health: the need for updating views on absolute product risks and harm reduction. BMC Public Health 2016;16:432.

18 Abrams DB. Promise and peril of e-cigarettes: can disruptive technology make cigarettes obsolete? JAMA 2014;311:135-6.

19 Levy DT, Cummings KM, Villanti AC, et al. A framework for evaluating the public health impact of e-cigarettes and other vaporized nicotine products. Addiction 2017;112:8-17. 
20 Levy DT, Borland R, Villanti AC, et al. The Application of a Decision-Theoretic Model to Estimate the Public Health Impact of Vaporized Nicotine Product Initiation in the United States. Nicotine Tob Res 2017;19:149-59.

21 Warner KE. An endgame for tobacco? Tob Control 2013;22(Suppl 1):i3-5.

22 Fairchild AL, Bayer R, Colgrove J. The renormalization of smoking? E-cigarettes and the tobacco "endgame". N Eng/ J Med 2014;370:293-5.

23 Kalkhoran S, Glantz SA. E-cigarettes and smoking cessation in real-world and clinical settings: a systematic review and meta-analysis. Lancet Respir Med 2016;4:116-28.

24 Kalkhoran S, Grana RA, Neilands TB, et al. Dual use of smokeless tobacco or e-cigarettes with cigarettes and cessation. Am J Health Behav 2015;39:277-84.

25 McKee M, Chapman S, Daube M, et al. The debate on electronic cigarettes. Lancet 2014;384:2107.

26 Hecht SS, Carmella SG, Kotandeniya D, et al. Evaluation of toxicant and carcinogen metabolites in the urine of e-cigarette users versus cigarette smokers. Nicotine Tob Res 2015;17:704-9.

27 Royal College of Physicians. Nicotine without smoke: Tobacco harm reduction. London: RCP, 2016.

28 Goniewicz ML, Knysak J, Gawron M, et al. Levels of selected carcinogens and toxicants in vapour from electronic cigarettes. Tob Control 2014;23:133-9.

29 Wagener TL, Floyd EL, Stepanov I, et al. Have combustible cigarettes met their match? The nicotine delivery profiles and harmful constituent exposures of second-generation and third-generation electronic cigarette users. Tob Control 2017;26:e23-8.

30 Glasser AM, Collins L, Pearson JL, et al. Overview of electronic nicotine delivery systems: A systematic review. Am J Prev Med 2017;52:e33-66.

31 Shahab L, Goniewicz ML, Blount BC, et al. Nicotine, carcinogen, and toxin exposure in long-term e-cigarette and nicotine replacement therapy users: a Cross-sectional Study. Ann Intern Med 2017;166:390.

32 Goniewicz ML, Gawron M, Smith DM, et al. Exposure to Nicotine and Selected Toxicants in Cigarette Smokers Who Switched to Electronic Cigarettes: A Longitudinal Within-Subjects Observational Study. Nicotine Tob Res 2017;19:160-7.

33 Farsalinos KE, Spyrou A, Tsimopoulou K, et al. Nicotine absorption from electronic cigarette use: comparison between first and new-generation devices. Sci Rep 2014;4:4133.

34 Dawkins L, Turner J, Roberts A, et al. 'Vaping' profiles and preferences: an online survey of electronic cigarette users. Addiction 2013;108:1115-25.

35 Holford TR, Levy DT, McKay LA, et al. Patterns of birth cohort-specific smoking histories, 1965-2009. Am J Prev Med 2014;46:e31-7.

36 Rosenberg MA, Feuer EJ, Yu B, et al. Chapter 3: Cohort life tables by smoking status, removing lung cancer as a cause of death. Risk Anal 2012;32(Suppl 1):S25-38.

37 Institute of Medicine. Public health implications of raising the minimum age of legal access to tobacco products. Washingon, DC: National Academy Press, 2015.

38 Doll R, Peto R, Boreham J, et al. Mortality in relation to smoking: 50 years' observations on male British doctors. BMJ 2004:328:1519.

39 Villanti AC, Pearson JL, Glasser AM, et al. Frequency of youth e-cigarette and tobacco use patterns in the U.S.: Measurement precision is critical to inform public health. Nicotine Tob Res 2016:ntw388.

40 Delnevo CD, Giovenco DP, Steinberg MB, et al. Patterns of Electronic Cigarette Use Among Adults in the United States. Nicotine Tob Res 2016;18:715-9.

41 Warner KE. Frequency of E-Cigarette Use and Cigarette Smoking by American Students in 2014. Am J Prev Med 2016;51:179-84.

42 Dawkins L, Corcoran O. Acute electronic cigarette use: nicotine delivery and subjective effects in regular users. Psychopharmacology 2014;231:401-7.

43 Spindle TR, Breland AB, Karaoghlanian NV, et al. Preliminary results of an examination of electronic cigarette user puff topography: the effect of a mouthpiece-based topography measurement device on plasma nicotine and subjective effects. Nicotine Tob Res 2015:17:142-9.

44 Vansickel AR, Eissenberg T. Electronic cigarettes: effective nicotine delivery after acute administration. Nicotine Tob Res 2013:15:267-70.

45 Liu G, Wasserman E, Kong L, et al. A comparison of nicotine dependence among exclusive E-cigarette and cigarette users in the PATH study. Prev Med 2017.
46 Nutt DJ, Phillips LD, Balfour D, et al. Estimating the harms of nicotine-containing products using the MCDA approach. Eur Addict Res 2014;20:218-25.

47 Glantz SA. Need for examination of broader range of risks when predicting the effects of new tobacco products. Nicotine Tob Res 2017;19:266-7.

48 Glantz SA. UCSF Blog, 2017. https://tobacco.ucsf.edu/evidence-e-cigs-increasecardiovascular-risk-keeps-piling-effects-heart-rhythm-and-oxidative-stress

49 Levy DT, Borland R, Villanti AC, et al. The Application of a Decision-Theoretic Model to Estimate the Public Health Impact of Vaporized Nicotine Product Initiation in the United States. Nicotine Tob Res 2017;19:149-59.

50 Czogala J, Goniewicz ML, Fidelus B, et al. Secondhand exposure to vapors from electronic cigarettes. Nicotine Tob Res 2014;16:655-62.

51 McAuley TR, Hopke PK, Zhao J, et al. Comparison of the effects of e-cigarette vapor and cigarette smoke on indoor air quality. Inhal Toxicol 2012;24:850-7.

52 Cobb CO, Villanti AC, Graham AL, et al. Markov Modeling to Estimate the Population Impact of Emerging Tobacco Products: A Proof-of-Concept Study. Tob Regul Sci 2015;1:129-41.

53 Cherng ST, Tam J, Christine PJ, et al. Modeling the Effects of E-cigarettes on Smoking Behavior: Implications for Future Adult Smoking Prevalence. Epidemiology 2016:27:819-26.

54 Kalkhoran S, Glantz SA. Modeling the Health Effects of Expanding e-Cigarette Sales in the United States and United Kingdom: A Monte Carlo Analysis. JAMA Intern Med 2015;175:1671-80.

55 King BA, Patel R, Nguyen $\mathrm{KH}$, et al. Trends in awareness and use of electronic cigarettes among US adults, 2010-2013. Nicotine Tob Res 2015;17:219-27.

56 Marynak KL, Gammon DG, King BA, et al. National and State Trends in Sales of Cigarettes and E-Cigarettes, U.S., 2011-2015. Am J Prev Med 2017;53:96-101.

57 Delnevo CD, Hrywna M, Foulds J, et al. Cigar use before and after a cigarette excise tax increase in New Jersey. Addict Behav 2004;29:1799-807.

58 Levy D, Mohlman MK, Zhang Y. Estimating the Potential Impact of Tobacco Control Policies on Adverse Maternal and Child Health Outcomes in the United States Using the SimSmoke Tobacco Control Policy Simulation Model. Nicotine Tob Res 2016;18:1240-9.

59 Ahmad S, Franz GA. Raising taxes to reduce smoking prevalence in the US: a simulation of the anticipated health and economic impacts. Public Health 2008; 122:3-10.

60 Levy DT, Mabry PL, Graham AL, et al. Reaching Healthy People 2010 by 2013: A SimSmoke simulation. Am J Prev Med 2010;38(3 Suppl):S373-81.

61 Levy DT, Mays D, Yuan Z, et al. Public health benefits from pictorial health warnings on US cigarette packs: a SimSmoke simulation. Tob Control 2017;26:649-55.

62 Levy DT, Lindblom EN, Fleischer NL, et al. Public Health Effects of Restricting Retail Tobacco Product Displays and Ads. Tob Regul Sci 2015;1:61-75.

63 Donny EC, Hatsukami DK, Benowitz NL, et al. Reduced nicotine product standards for combustible tobacco: building an empirical basis for effective regulation. Prev Med 2014:68:17-22.

64 Smith TT, Sved AF, Hatsukami DK, et al. Nicotine reduction as an increase in the unit price of cigarettes: a behavioral economics approach. Prev Med 2014:68:23-8.

65 Hatsukami DK, Luo X, Dick L, et al. Reduced nicotine content cigarettes and use of alternative nicotine products: exploratory trial. Addiction 2017;112:156-67.

66 Levy DT, Pearson JL, Villanti AC, et al. Modeling the future effects of a menthol ban on smoking prevalence and smoking-attributable deaths in the United States. Am J Public Health 2011;101:1236-40.

67 Chaloupka FJ, Sweanor D, Warner KE. Differential taxes for differential risks-toward reduced harm from nicotine-yielding products. N Engl J Med 2015;373:594-7.

68 Stoklosa M, Drope J, Chaloupka FJ. Prices and E-Cigarette Demand: Evidence From the European Union. Nicotine Tob Res 2016;18:1973-80.

69 Czoli CD, Goniewicz M, Islam T, et al. Consumer preferences for electronic cigarettes: results from a discrete choice experiment. Tob Control 2016;25:e30-6.

70 McDaniel PA, Smith EA, Malone RE. Philip Morris's Project Sunrise: weakening tobacco control by working with it. Tob Control 2006:15:215-23.

71 World Health Organization. WHO Report on the Global Tobacco Epidemic, 2008: The MPOWER package. Geneva: World Health Organization 2008. 